\title{
The Correlation of Sexual Dysfunction with Prenatal Stress and Quality of Life: A Path Analysis
}

\author{
Farzane Alidost, ${ }^{1}$ Mahrokh Dolatian, ${ }^{1,}{ }^{*}$ Jamal Shams, ${ }^{2}$ Malihe Nasiri, ${ }^{3,4}$ and Ebrahim Sarkhoshpour ${ }^{5}$ \\ ${ }^{1}$ Department of Midwifery, School of Nursing and Midwifery, Shahid Beheshti University of Medical Sciences, Tehran, IR Iran \\ ${ }^{2}$ Associated Professor Psychiatry, Behavioral Research Center, Department of Psychiatry, Shahid Beheshti University of Medical Science, Tehran, IR Iran \\ ${ }^{3}$ Assistant Professor, School of Nursing and Midwifery, Shahid Beheshti University of Medical Sciences, Tehran, IR Iran \\ ${ }^{4}$ Department of Biostatistics, Faculty of Paramedical, Shahid Beheshti University of Medical Sciences, Tehran, IR Iran \\ ${ }^{5}$ Anesthesiology Department, School of Paramedical Sciences, Bushehr University of Medical Sciences, Bushehr, IR Iran \\ "Corresponding author: Mahrokh Dolatian, Department of Midwifery, School of Nursing and Midwifery, Shahid Beheshti University of Medical Sciences, Tehran, IR Iran. Tel: \\ +98-2188202512, E-mail: mhdolatian@gmail.com
}

Received 2017 February 14; Revised 2017 March 17; Accepted 2017 April 24.

\begin{abstract}
Background: Women are exposed to different stressors in life. Physical, emotional, and economic stressors of pregnancy might negatively affect couples' emotional and sexual intimacy.

Objectives: The present study was designed to perform a path analysis of the correlation of sexual dysfunction with prenatal stress and quality of life.

Methods: In this descriptive, correlational study, 300 pregnant Iranian women were recruited via convenience sampling, based on the inclusion criteria from 4 governmental referral hospitals in 2016. Data were collected using female sexual function index, 26-item world health organization quality of life questionnaire, prenatal anxiety questionnaire, and a demographic questionnaire. Results: The goodness of fit indices (GFI) in the model indicated the suitability and reasonability of relationships among variables (root mean square error of approximation, 0.023; GFI, 0.99). Quality of life and age directly affected sexual dysfunction, while prenatal anxiety and income were indirectly correlated with sexual dysfunction through quality of life $(\mathrm{P}<0.01)$. Other variables did not show any significant correlations.

Conclusions: Anxiety can decrease sexual function in women during pregnancy. Poor quality of life can also cause sexual dysfunction in pregnant women. Therefore, it is an undeniable necessity to take measures to reduce prenatal anxiety and promote sexual activity during pregnancy for ensuring marital satisfaction. In addition, through such measures, we can maintain/improve the general and sexual health of couples, increase the quality of life in pregnant women, and eventually strengthen family bonds.
\end{abstract}

Keywords: Pregnancy, Anxiety, Quality of Life, Sexual Dysfunction, Path

\section{Background}

Sexual dysfunctions, including dyspareunia, sexual desire disorder, sexual arousal disorder, and orgasmic dysfunction, are major public health concerns, which can disturb an individual's daily life and interpersonal relationships (1). According to a study by Basson et al., sexual dysfunction is associated with a persistent or recurrent reduction in sexual desire or arousal, dyspareunia, and orgasmic dysfunction (2).

Sexual problems are of great importance in marriage, and adaptation in sexual relationship is an important factor affecting couples' happiness and satisfaction (3). Since disregard of sexuality can leave irreversible effects on individuals, sexual dysfunction and dissatisfaction may lead to the collapse of the family unit (4). According to a study in Iran, the prevalence of hypoactive sexual desire disorder, sexual arousal disorder, inadequate vaginal lubrication during intercourse, orgasmic dysfunction, sexual dissatisfaction, and dyspareunia was 35.6\%, 39.9\%, 18.9\%, 27.3\%,
$15.2 \%$, and 56.1\% among women, respectively (5). Moreover, Ebrahimian et al. (2010) reported the prevalence of sexual dysfunction in Iran to be $20 \%$ - 40\% (6).

Exposure of pregnant women to different problems during pregnancy increases the levels of anxiety and stress. These problems include physical symptoms, significant biological and biochemical changes, possible changes in personal and family relationships, socioeconomic problems, obstetric factors related to pregnancy, infant health, and labor stages (7, 8). In fact, stressful physical, emotional, and financial factors related to pregnancy may negatively affect emotional and sexual intimacy (9).

In this regard, Takahasi (2013) reported the prevalence of prenatal stress and anxiety to be $24.9 \%$ (10). Overall, sexual desire and activity of pregnant women and their partners are unpredictable and may increase, decrease, or remain unchanged during pregnancy. Each of these changes can leave long-term negative effects on maternal sexuality and mental health (11). 
According to the world health organization (WHO), quality of life is defined as an individual's perception of his/her position in life in the cultural context and value system of the society he/she lives in. These perceptions are developed based on the goals, wishes, expectations, standards, and concerns $(12,13)$. On the other hand, pregnancy considerably affects physical, mental, and social health, i.e., quality of life of pregnant women (14).

Quality of life measurements during pregnancy are particularly important in planning maternal and infant care and highlight the necessity of such care for health policymakers and organizations (15). Considering the risky and stressful conditions of pregnant women and the significance of sexual desire and function in their health, it is necessary to ensure marital satisfaction, maintain/improve couples' general and sexual health, and strengthen family bonds in order to reduce prenatal stress and promote sexual activity during pregnancy (1).

People with sexual disorders usually tend to hide or resolve their problems at home. Since these symptoms are often left unsaid and thus untreated, they become chronic and lead to mental and mood disorders, anxiety, introversion, and feelings of guilt (16). According to previous studies, although women with acute stress are less aroused by erotic stimuli, chronic stress has no effects on sexual arousal (17). In this regard, Ein-Dor et al. indicated increased sexual function after a stressful day among couples with satisfying marital relations (18).

Limited studies have evaluated prenatal stress and anxiety (19), and there is a lack of evidence on the possible correlation of prenatal stress with sexual dysfunction and quality of life in Iran. Most relevant studies have addressed the correlation between stress and quality of life or have analyzed quality of life in women with sexual dysfunction during pregnancy. However, no study has assessed the direct or indirect effects of these factors, and no path analysis has been conducted on sexual dysfunction in pregnancy with simultaneous assessment in a model; therefore, further studies are required in this area.

\section{Methods}

This descriptive, correlational study was conducted on 300 pregnant Iranian women (age range, 15 - 45 years), who were referred to the selected hospitals to receive prenatal care services in 2016. The inclusion criteria were ability to read and write, Iranian nationality, wanted pregnancy, living with the partner, and no history of alcohol use, smoking, or medication use affecting libido (e.g., antidepressants and blood pressure medications). On the other hand, women with high-risk pregnancies (according to obstetric definitions), medical restrictions on intercourse during pregnancy, and history of physical or mental diseases were not included.

\subsection{Assessment Tools}

The data were collected using a demographic form, an asset index, female sexual function index (FSFI), who quality of life questionnaire (WHOQOL-BREF), and prenatal anxiety questionnaire. The demographic form contained personal and obstetric information, such as age, number of children, level of education, duration of marriage, and place of residence.

\subsection{Asset Index}

This researcher-made questionnaire examined 12 economic variables (owning a vacuum cleaner, a separate kitchen, a computer, a washing machine, a bathroom, a freezer, a dishwasher, a private car not used for work or money-making, a mobile phone, a color TV, a video player, and a landline telephone). The asset indices were calculated as percentage and classified into 5 categories, including very poor ( 0 - 20), poor (21 - 40), average (41 - 60), rich $(61-80)$, and very rich $(81-100)(20,21)$.

\subsection{Prenatal Anxiety Questionnaire}

This 25-item questionnaire was a combination of a 10item questionnaire by Huizink et al. (a short form of Van den Berg's 55-item questionnaire, 2004) and some personal-familial factors, originally listed in Van den Berg's questionnaire. The questions were arranged in 6 subscales, including maternal health (6 items), infant health (5 items), childbirth and maternal experience (4 items), interests of children and mothers (2 items), personal/familial interests (5 items), and personal/career interests ( 3 items). The items were scored on a 5 -point Likert scale (never, 0; rarely, 1 ; sometimes, 2; most often, 3; always, 4), and the total scores ranged between 0 and 100. Navidpour et al. confirmed the reliability and validity of this questionnaire (22).

\subsection{FSFI}

This 19-item questionnaire evaluated female sexual function in 6 domains, including sexual desire (items 1 and 2), sexual arousal (items 3 - 6), vaginal lubrication (items 7 10), orgasm (items 11 - 13), sexual satisfaction (items 14 -16), and dyspareunia (items 17 - 19). Each item was scored from 1 to 5 in the sexual desire domain and from 0 to 5 in other domains. The score of each domain was calculated by summing the scores of items and multiplying the value by the domain coefficient. Sexual desire, sexual arousal, vaginal lubrication, orgasm, sexual satisfaction, and dyspareunia coefficients were $0.6,0.3,0.3,0.4,0.4$, and 0.4 , respectively. 
The score of sexual desire domain ranged between 1.2 and 6 , and the scores of other domains ranged between 0 and 6; higher scores indicated better sexual function. Based on this questionnaire, a total score equal to or less than 26.5 was considered as female sexual dysfunction (23). Mohammadi et al. confirmed the reliability and validity of FSFI for assessing female sexual function in Iran (24).

\subsection{WHOQOL-BREF}

This 26-item questionnaire contained 4 domains of physical health (6 items), psychological health (6 items), environmental health (8 items), and social relationships (3 items). Two separate items evaluated the overall quality of life (first item) and general health (second item). Each item was scored from 1 to 5 (not at all, a little, moderate, very much, and extremely). The total score of each domain ranged between 4 and 20, with higher scores indicating better quality of life in that domain. The scores were converted to a 0 - 100 scale in this study (25).

Nedjat et al. (2008) assessed the reliability of WHOQOLBREF in Iran and reported Cronbach's alpha coefficients of $0.81,0.78,0.82$, and 0.80 for physical health, psychological health, social relationships, and environmental domains, respectively. Also, Nasiri and Jokar (2008) calculated a Cronbach's alpha coefficient of 0.84 and confirmed the construct validity of the questionnaire through factor analysis (26 items of the questionnaire could be arranged in 4 domains) (26). Likewise, Yousefy et al. (2010) confirmed the construct validity of WHOQOL-BREF and reported a reliability of 0.70 , using Cronbach's alpha (27).

\subsection{Procedure}

Upon the approval of the research project, permissions were obtained from the school of nursing and midwifery of Shahid Beheshti University of Medical Sciences (Tehran, Iran), and a letter of introduction was received. Four governmental referral hospitals were selected from 4 districts of Tehran, and the subjects were selected via convenience sampling according to the quota allocated to each hospital.

The study was conducted after obtaining permission from the chancellors of Shahid Beheshti University of Medical Sciences and hospital presidents. The researcher then visited the prenatal clinics of the selected hospitals, presented the introduction letter to the authorities, obtained permissions, and visited the clinics a few days a week for data collection. The patients were then evaluated, and eligible women were recruited.

The selected women were provided with details about the study objectives and procedure and were assured about the confidentiality of data and voluntary participation. They could withdraw from the study at any time and their privacy was respected. Informed consent forms were obtained from the participants, and they were asked to complete the questionnaires. After collecting the questionnaires, the data were analyzed.

The study was approved by the ethics committee of school of nursing, midwifery, and pharmacy, Shahid Beheshti University of Medical Sciences (ID: SBMU2.REC.1394.91) on 2015/10/8.

\subsection{Data Analysis}

The sample size in this study was calculated using the following formula:

Equation 1.

$\mathrm{n} \geq\left[\frac{\left(z_{1-\frac{\alpha}{2}}+z_{1-\beta}\right)}{0.5 \times \ln \left[\frac{(1+r)}{(1-r)}\right]}\right]^{2}+3$

Where $r$ denotes the correlation of sexual dysfunction with prenatal stress and quality of life. However, given the novelty of the subject and unavailability of relevant studies, $\mathrm{r}, \alpha$ (type I error), and $\beta$ (type II error) values were assumed to be $0.3,0.05$, and 0.1 , respectively (test power, 90\%).

Following data collection and encoding, the data were analyzed using SPSS version 23. First, descriptive indices, such as mean and standard deviation, were measured to determine the scores of stress, sexual dysfunction, and quality of life. Pearson's correlation coefficient was measured to assess the correlation of stress with sexual dysfunction and quality of life. Direct and indirect effects of prenatal stress and quality of life on sexual dysfunction were assessed in LISREL-8.8 using path analysis.

Path analysis is in fact an extension of regression model. Standardized regression coefficients indicate the direct effects of independent variables on dependent variables. Path analysis is recommended when a cause-effect relationship (instead of unreal or random relationships) holds between a series of variables, especially when there is a logical sequence among variables. Both direct and indirect paths, as well as the overall effects of causal relationships among variables, can be found through path analysis. The order of the effects of independent variables on dependent variables can be shown by drawing a diagram from left to right (28). P value less than 0.05 was considered statistically significant in this study.

\section{Results}

The mean age of women and their partners was 27.38 \pm 5.49 and $32.18 \pm 5.75$ years, respectively. The participants' 
Table 1. The Participants' Maximum and Minimum Scores on the Questionnaires

\begin{tabular}{|c|c|c|c|c|}
\hline Variables & Mean & SD & Minimum & Maximum \\
\hline Age & 27.38 & 5.49 & 16 & 43 \\
\hline Partner's age & 32.18 & 5.75 & 21 & 48 \\
\hline Education & 10.22 & 3.19 & 0 & 23 \\
\hline Partner's education & 10.00 & 3.27 & 0 & 23 \\
\hline Asset index & 68.80 & 21.66 & 0 & 100 \\
\hline Prenatal anxiety & 26.52 & 18.18 & 0 & 89 \\
\hline Quality of life & 249.01 & 38.60 & 126 & 357 \\
\hline Female sexual function & 21.29 & 11.32 & 2 & 36 \\
\hline
\end{tabular}

maximum and minimum scores on the questionnaires are presented in Table 1.

Based on the Pearson's correlation coefficients, women's age had a significant negative relationship with prenatal anxiety and sexual dysfunction. Likewise, partner's age had significant negative correlations with prenatal anxiety and sexual dysfunction. There was no significant correlation between the couple's age and quality of life. On the other hand, women's level of education was significantly and positively related to quality of life and sexual dysfunction.

No significant correlation was found between women's level of education and prenatal anxiety. Similarly, no significant correlation was observed between the partner's level of education and other variables. Moreover, asset index showed no significant correlation with sexual dysfunction. However, it was negatively correlated with prenatal anxiety and positively correlated with quality of life (Table 2).

Sexual function was directly affected by quality of life and age and indirectly by prenatal anxiety and financial assets. The effects of other variables were not significant (Table 3 and Figure 1).

$\chi^{2} / \mathrm{df}$, the desired value of this index is $<3$; goodnessof-fit index (GFI) and adjusted goodness-of-fit index (AGFI), these indices range between 0 and 1 (values $\geq 0.90$ indicate a well-fitting model); comparative fit index (CFI), this index ranges between 0 and 1 and values closer to 1 indicate a better fitting model; standardized root mean square residual (SRMR), it ranges from 0 to 1 and values $<0.05$ are more favorable; root mean square error of approximation (RMSEA), RMSEA values $<0.06$ are more favorable; TuckerLewis index or non-normed fit index (NNFI) and BentlerBonett index or normed fit index (NFI; values closer to 0.90 indicate more acceptable models, and consequently, all indices in this study were acceptable).

\section{Discussion}

The results of the present study showed that socioeconomic status indirectly affects sexual dysfunction through prenatal anxiety and quality of life. These results are consistent with those reported by Broumandfar et al. and Addis et al. (29, 30). Overall, previous research has highlighted the role of economic status in sexual dysfunction, indicating that people with low income are more likely to have sexual dysfunction $(16,31)$.

Marital dissatisfaction is associated with factors such as family bonds and socioeconomic status of couples and their families. Financial pressure is one of the factors, which can cause conflict between couples and affect their sexual activity (32). Our findings highlighted a significant correlation between quality of life and income level; in other words, higher income was associated with increased quality of life, reduced stress, and improved sexual function; several other studies have also reported similar results $(14,33-35)$. It seems reasonable to assume that better economic status can have positive effects on nutrition, care, awareness, and quality of life (36).

Bradley and Corwyn explained the relationship between socioeconomic status and health through a number of processes, the most important of which include access to social and financial resources and response to stress through various sources (37). There were also significant correlations between poor health before, during, and after pregnancy and inability to provide proper food and housing (38). In addition, previous studies have confirmed the correlation of low socioeconomic status with poor health and adverse pregnancy outcomes $(39,40)$.

The present study revealed that prenatal anxiety indirectly affects sexual dysfunction through a negative correlation with quality of life. Shahhosseini et al. argued that psychological disorders, such as stress, depression, and anxiety, are among factors affecting sexual satisfaction (41). 
Table 2. Correlation of Sexual Dysfunction with Demographic Variables, Prenatal Anxiety, and Quality of Life

\begin{tabular}{|c|c|c|c|c|c|c|c|c|}
\hline Variables & Age & Partner's Age & Education & $\begin{array}{c}\text { Partner's } \\
\text { Education }\end{array}$ & Asset Index & Prenatal Anxiety & Quality of Life & $\begin{array}{c}\text { Female Sexual } \\
\text { Function }\end{array}$ \\
\hline Age & 1 & $0.795^{\mathrm{a}}$ & -0.026 & -0.103 & $0.130^{\mathrm{b}}$ & $-0.171^{\mathrm{a}}$ & -0.034 & $0.178^{\mathrm{a}}$ \\
\hline Partner's age & & 1 & -0.095 & -0.104 & $0.209^{\mathrm{a}}$ & $-0.195^{\mathrm{a}}$ & -0.036 & $-0.120^{b}$ \\
\hline Education & & & 1 & $0.607^{\mathrm{a}}$ & $0.413^{\mathrm{a}}$ & -0.013 & $0.129^{\mathrm{b}}$ & $0.133^{\mathrm{b}}$ \\
\hline $\begin{array}{l}\text { Partner's } \\
\text { education }\end{array}$ & & & & 1 & $0.380^{\mathrm{a}}$ & 0.046 & 0.106 & 0.87 \\
\hline Asset index & & & & & 1 & $-0.170^{\mathrm{a}}$ & $0.205^{\mathrm{a}}$ & 0.67 \\
\hline Prenatal anxiety & & & & & & 1 & $-0.201^{\mathrm{a}}$ & -0.51 \\
\hline Quality of life & & & & & & & 1 & $0.238^{\mathrm{a}}$ \\
\hline $\begin{array}{l}\text { Female sexual } \\
\text { function }\end{array}$ & & & & & & & & 1 \\
\hline $\begin{array}{l}{ }^{\mathrm{a}} \text { Significant at 0.01. } \\
{ }^{\mathrm{b}} \text { Significant at } 0.05 .\end{array}$ & & & & & & & & \\
\hline
\end{tabular}

Table 3. Direct and Indirect Effects of Variables on Sexual Dysfunction

\begin{tabular}{lcccc}
\hline Variables & Direct & Indirect & Total & T value \\
\hline Quality of life & 0.22 & 0 & 0.22 & $-0.03,0.04$ \\
Prenatal anxiety & -0.03 & $-0.04^{*}$ & -0.07 & $-0.02,-0.06$ \\
\hline Age & -0.18 & 0.001 & -0.179 & $-0.02,0.02$ \\
Asset index & 0.04 & $0.05^{*}$ & 0.09 & $-0.03,0.07$ \\
Partner's age & 0 & 0.01 & 0.01 & $-0.03,0.05$ \\
Education & 0 & 0.001 & 0.001 & $-0.04,0.04$ \\
\hline Partner's education & 0 & -0.01 & -0.01 & $-0.04,0.02$ \\
\hline
\end{tabular}

Sexual responses are a result of the mutual effects of physical (depression, stress, and administered medications), psychological (chronic stress, fatigue, sexual identity, and gender-related issues), and communication factors (42). Furthermore, Brizendin noted that stressful women less commonly express their feelings and desires since cortisol impedes oxytocin function in the brain and prevents female desire for physical and sexual relationships (43).

Overall, when an individual is exposed to stressors, such as needs or threats, two basic physiological events occur. The first event involves the autonomic nervous system and secretion of catecholamines, especially norepinephrine and epinephrine. The next event occurs in the hypothalamic-pituitary-adrenal axis and causes the secretion of corticotropin, adrenocorticotropin, and cortisol. Not only do these events lead to physiological responses, but also cause behavioral changes, including loss of appetite, reduced sexual activity, and increased feelings of depression, anxiety, aggression, and irritation (44, 45).

Based on the findings, prenatal stress had significant impacts on sexual satisfaction and libido (the first phase among 4 phases of sexual response). Overall, depression can lead to decreased libido and sexual function. Libido and sexual satisfaction are in turn correlated with various aspects of quality of life and mental health (depression, stress, and anxiety) (34). Many studies have introduced mental health as the most influential factor in sexual satisfaction. Mental health refers to a person's perceptions of life and sexual/interpersonal relationships $(46,47)$. It is a relative and positive measure of different aspects of life, creating a balance between positive (e.g., happiness, determination, self-confidence, and positive body image) and negative (e.g., anxiety, stress, and depression) emotions (48).

Sexual dysfunction can be both caused by and lead to mental health problems (49). Low quality of life can increase stress and cause sexual dysfunction (50). The results of this study showed that quality of life could directly affect sexual dysfunction. According to previous research, decreased physical activity, limited social function, and emotional problems can reduce quality of life during pregnancy $(50,51)$. 


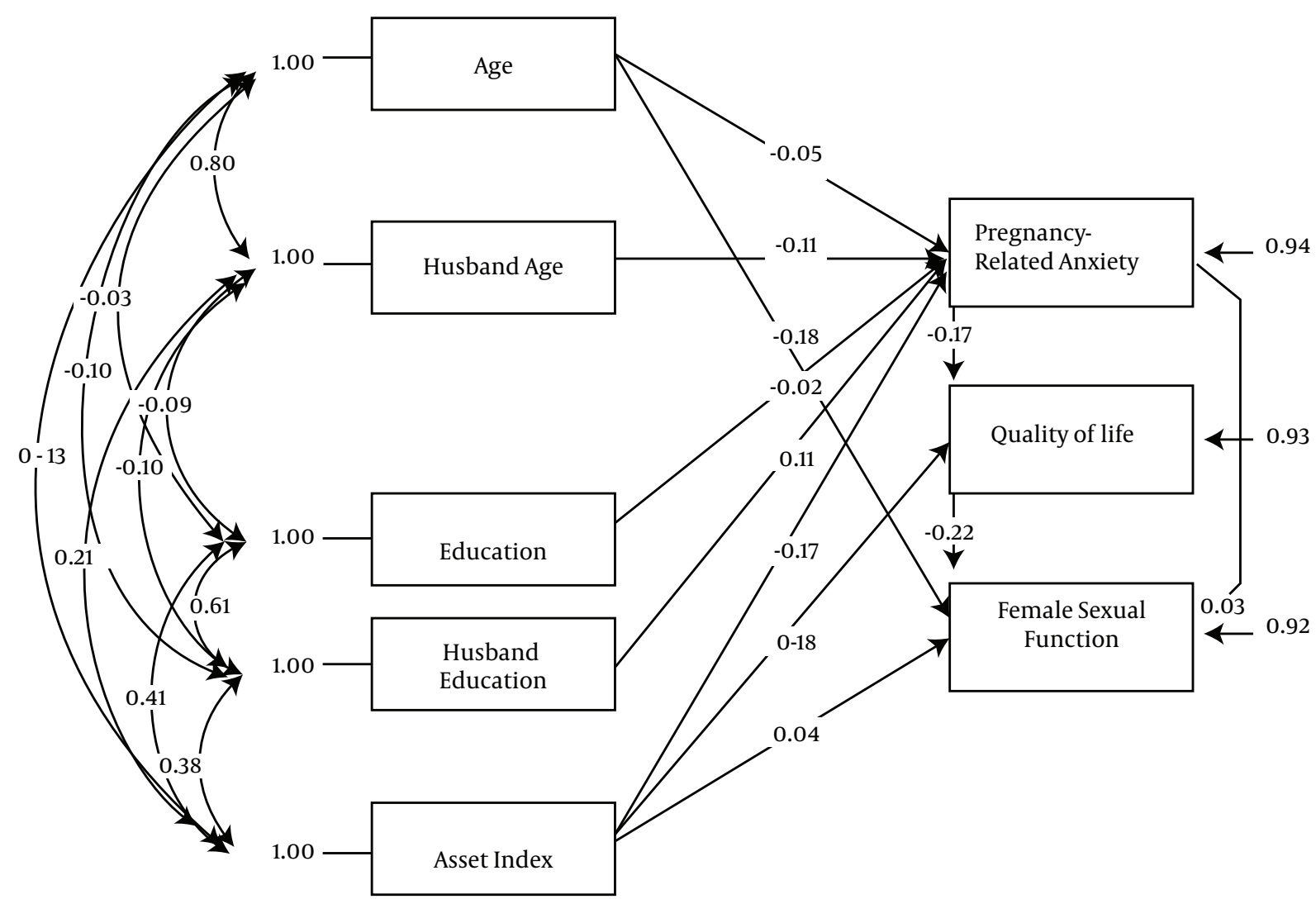

Figure 1. The Effects of Demographic Variables, Prenatal Anxiety, and Quality of Life on Sexual Dysfunction ( $\chi^{2}$ /df, 1.1; GFI, 0.99; AGFI, 0.97; CFI, 1; SRMR, 0.031; RMSEA, 0.023; NFI, 0.99)

Furthermore, poor quality of life can increase stress and cause sexual dysfunction. Sexual dysfunction has a major effect on quality of life and interpersonal relations. In fact, many women consider this problem physically disturbing, emotionally upsetting, and socially destructive (52). High levels of sexual dysfunction in women may endanger their health and quality of life due to feelings of embarrassment and inability to sexually satisfy their partner (31).

The present findings indicated a significant negative correlation between age and sexual dysfunction. Many studies have shown a relationship between sexual dysfunction and aging $(42,49,53,54)$. Since aging affects the sexual response cycle and physiology and causes hormonal changes in the body, libido, frequency of sexual intercourse, and marital satisfaction may decrease with advancing age (55). Age may affect sexual function through lifestyle or psychosocial changes (52). Yoo et al. and Ramezanitehrani et al. reported that women's sexual activity was affected by aging due to new commitments in life, such as childcare and other responsibilities in the family and society $(5,56)$.

\subsection{Conclusion}

The results of the present study showed that age, quality of life, prenatal anxiety, and asset index affect sexual dysfunction in pregnant women. Stress can deteriorate female sexual function during pregnancy. Continued sexual activity during pregnancy increases selfknowledge and sexual performance and strengthens marital relationship and sexual activity. On the other hand, poor quality of life can cause sexual dysfunction in pregnant women. Therefore, increasing marital satisfaction, maintaining/improving general and sexual health of couples, increasing quality of life in pregnant women, and finally strengthening family bonds require efforts to reduce prenatal anxiety and facilitate sexual activity during pregnancy. 


\subsection{Strengths of the Study}

Most relevant studies have addressed the relationship and correlation between stress and quality of life in women with sexual dysfunction during pregnancy, while no study has assessed the direct or indirect effects of these factors. Also, sexual dysfunction in pregnancy has not been examined through path analysis with simultaneous assessment in a model; this in fact indicates the need for future research. Another strength of the present study was the use of a standard tool for sexual function rather than relying on self-reports of sexual problems.

\subsection{Limitations}

Since the sexual dysfunction questionnaire contained questions about personal issues and it was possible for the subjects to feel embarrassed while responding to the questions, the researcher tried to minimize these limitations by explaining the importance of the study, assuring them about the confidentiality of the data, and obtaining their consent.

\section{Acknowledgments}

This article was extracted from a Master's thesis in midwifery. We would like to thank all the participants, authorities, and managers for their cooperation.

\section{Footnote}

Financial Disclosure: Conflicts of Interests;

\section{References}

1. Ibrahim ZM,Ahmed MR, Sayed Ahmed WA. Prevalence and risk factors for female sexual dysfunction among Egyptian women. Arch Gynecol Obstet. 2013;287(6):1173-80. doi: 10.1007/s00404-012-2677-8. [PubMed: 23274790].

2. Basson R, Berman J, Burnett A, Derogatis L, Ferguson D, Fourcroy J, et al. Report of the international consensus development conference on female sexual dysfunction: definitions and classifications. $J$ Urol. 2000;163(3):888-93. doi: 10.1097/00005392-200003000-00043. [PubMed: 10688001].

3. Jamshidi Manesh M, Jouybary L, Peyrovi H, Sanagoo A. The ups and downs of sex life in menopausal stage: a qualitative study[In Persian]. Qom Univ Med Sci J. 2009;3(2):41-6.

4. Pakgohar M, Vizheh M, Babaee G, Ramezanzadeh F, Abedininia N. Effect of counseling on sexual satisfaction among infertile women referred to Tehran fertility center [In Persian]. J Hayat. 2008;14(1):21-30.

5. Ramezani Tehrani F, Farahmand M, Mehrabi Y, Malekafzali H, Abedini M. Prevalence of female sexual dysfunction and its correlated factors: a population based study [In Persian]. Payesh. 2012;11(6):869-75.

6. Ebrahimian A, Heydari M, Saberi Zafarghandi M. Comparison of female sexual dysfunctions before and during pregnancy [In Persian]. Iran J Obstet Gynecol Infertil. 2010;13(5):30-6.

7. Dunkel Schetter C. Psychological science on pregnancy: stress processes, biopsychosocial models, and emerging research issues. Annu Rev Psychol. 2011;62:531-58. doi: 10.1146/annurev.psych.031809.130727. [PubMed: 21126184].
8. van Bussel JC, Spitz B, Demyttenaere K. Anxiety in pregnant and postpartum women. An exploratory study of the role of maternal orientations. J Affect Disord. 2009;114(1-3):232-42. doi: 10.1016/j.jad.2008.07.018. [PubMed: 18793805].

9. Qavam M, Tasbihsazan R. Prevalence of married male \& female sexual dysfunction to family heaith clinic.J Oromieh Med Sci. 2007;18(4):6349.

10. Takahasi EH, Alves MT, Alves GS, Silva AA, Batista RF, Simoes VM, et al. Mental health and physical inactivity during pregnancy: a crosssectional study nested in the BRISA cohort study. Cad Saude Publica. 2013;29(8):1583-94. doi: 10.1590/S0102-311X2013001200011. [PubMed: 24005924].

11. Eryilmaz G, Ege E, Zincir H. Factors affecting sexual life during pregnancy in eastern Turkey. Gynecol Obstet Invest. 2004;57(2):103-8. doi: 10.1159/000075582. [PubMed: 14673220].

12. White ML. Spirituality Self-care Effects on quality of life for patients diagnosed with chronic illness. Bulletin Luxembourgeois Des Questions Sociales. 2012;29:285-304.

13. Momeni K, Shahbazirad A. Relationship of spirituality, resiliency, and coping strategies with quality of life in university students [In Persian]. J Behav Sci. 2012;6:97-103.

14. Abbaszadeh F, Baghery A, Mehran N. Quality of life among pregnant women [In Persian]. J Hayat. 2009;15(1):41-8.

15. Abedian Z, Nikpour M, Mokhber N, Ebrahimi S, Khani S. Evaluation of relationship between delivery mode and postpartum quality of life [In Persian]. Iran J Obstet Gynecol Infertil. 2010;13(3):47-53.

16. Bakouei F, Omidvar S, Nasiri F. Prevalence of female sexual dysfunction in married women and its related factors (Babol 2006) [In Persian]. J Babol Univ Med Sci. 2007;9(4):59-64.

17. Ter Kuile MM, Vigeveno D, Laan E. Preliminary evidence that acute and chronic daily psychological stress affect sexual arousal in sexually functional women. Behav Res Ther. 2007;45(9):2078-89. doi: 10.1016/j.brat.2007.03.006. [PubMed: 17481578].

18. Ein-Dor T, Hirschberger G. Sexual healing Daily diary evidence that sex relieves stress for men and women in satisfying relationships. J Soc Pers Relat. 2012;29(1):126-19. doi: 10.1177/0265407511431185.

19. Huizink AC, Mulder EJ, Robles de Medina PG, Visser GH, Buitelaar JK. Is pregnancy anxiety a distinctive syndrome?. Early Hum Dev. 2004;79(2):81-91. doi: 10.1016/j.earlhumdev.2004.04.014. [PubMed: 15324989].

20. Baheiraei A, Hamzehgardeshi Z, Mohammadi MR, Nedjat S, Mohammadi E. Lifetime and current waterpipe use among adolescents in Tehran, Islamic Republic of Iran. East Mediterr Health J. 2013;19(12):1003-13. [PubMed: 24684098].

21. Kiani Z, Simbar M, Dolatian M, Zayeri F. Correlation between Social Determinants of Health and Women's Empowerment in Reproductive Decision-Making among Iranian Women. Glob J Health Sci. 2016;8(9):54913. doi: 10.5539/gjhs.v8n9p312. [PubMed: 27157184].

22. Navidpour F, Dolatian M, Yaghmaei F, Majd HA, Hashemi SS. Examining Factor Structure and Validating the Persian Version of the Pregnancy's Worries and Stress Questionnaire for Pregnant Iranian Women. GlobJHealth Sci. 2015;7(6):308-18. doi:10.5539/gjhs.v7n6p308. [PubMed: 26153186].

23. Rosen R, Brown C, Heiman J, Leiblum S, Meston C, Shabsigh R, et al. The Female Sexual Function Index (FSFI): a multidimensional self-report instrument for the assessment of female sexual function.J Sex Marital Ther. 2000;26(2):191-208. doi:10.1080/009262300278597.[PubMed: 10782451].

24. Mohammadi K, HEYDARI M, Faghihzadeh S. The female sexual function index (FSFI): validation of the Iranian version [In Persian]. Payesh. 2008;7(3):269-78.

25. Organization WH. WHOQOL-BREF: introduction, administration, scoring and generic version of the assessment: field trial version, December 1996. 1996 
26. Nedjat S, Montazeri A, Holakouee K, Mohammad K, Majdzadeh SR. Standardization of the world health organization quality of life questionnaire (WHOQOL-BREF): Translation and psychometric assessment of Iranian species. J School Health. 2006;4(4):12-1.

27. Yousefy AR, Ghassemi GR, Sarrafzadegan N, Mallik S, Baghaei AM, Rabiei K. Psychometric properties of the WHOQOL-BREF in an Iranian adult sample. Community Ment Health J. 2010;46(2):139-47. doi: 10.1007/s10597-009-9282-8. [PubMed: 20063062].

28. Vieira AL. Interactive LISREL in practice. New York: Springer; 2011.

29. Addis IB, Van Den Eeden SK, Wassel-Fyr CL, Vittinghoff E, Brown JS, Thom DH, et al. Sexual activity and function in middleaged and older women. Obstet Gynecol. 2006;107(4):755-64. doi: 10.1097/01.AOG.0000202398.27428.e2. [PubMed:16582109].

30. Broumandfar K, Farajzadegan Z, Hoseini H, Ghaed Rahmati M. Reviewing sexual function after delivery and its association with some of the demographic marital satisfaction factors [In Persian]. Alborz Univ Med J. 2012;1(2):93-9.

31. Amidu N, Owiredu WK, Woode E, Addai-Mensah O, Quaye L, Alhassan A, et al. Incidence of sexual dysfunction: a prospective survey in Ghanaian females. Reprod Biol Endocrinol. 2010;8:106. doi: 10.1186/14777827-8-106. [PubMed: 20809943].

32. Mohammad-Alizadeh-Charandabi S, Mirghafourvand M, AsghariJafarabadi M, Tavananezhad N, Karkhaneh M. Modeling of sociodemographic predictors of sexual function in women of reproductive age [In Persian]. J Mazandaran Univ Med Sci. 2014;23(110):238-42.

33. Barriuso-Lapresa L, Hernando-Arizaleta L, Rajmil L. Social inequalities in mental health and health-related quality of life in children in Spain. Pediatrics. 2012;130(3):e528-35. doi: 10.1542/peds.2011-3594. [PubMed: 22908114].

34. Nik-Azin A, Nainian MR, Zamani M, Bavojdan MR, Bavojdan MR, Motlagh MJ. Evaluation of sexual function, quality of life, and mental and physical health in pregnant women. J Family Reprod Health. 2013;7(4):171-6. [PubMed: 24971121].

35. Heiydari S, Salahshorian A, Rafie F, Hoseini F. Correlation of perceived social support and size of social network with quality of life dimension in cancer patients [In Persian]. Feyz J Kashan Univ Med Sci. 2008;12(2).

36. Tahery N, Kamangar S, Cheraghian B, Mousavi SZO, Solaimanzadeh M. Quality of life in hemodialysis patients. J Knowledge Health. 2013;8:11924.

37. Bradley RH, Corwyn RF. Socioeconomic status and child development. Annu Rev Psychol. 2002;53:371-99. doi: 10.1146/annurev.psych.53.100901.135233. [PubMed: 11752490].

38. Haas JS, Jackson RA, Fuentes-Afflick E, Stewart AL, Dean ML, Brawarsky $P$, et al. Changes in the health status of women during and after pregnancy. J Gen Intern Med. 2005;20(1):45-51. doi: 10.1111/j.15251497.2004.40097.x. [PubMed: 15693927].

39. Hemingway H, Nicholson A, Stafford M, Roberts R, Marmot M. The impact of socioeconomic status on health functioning as assessed by the SF-36 questionnaire: the Whitehall II Study. Am J Public Health. 1997;87(9):1484-90. [PubMed: 9314801].

40. Maddahi MS, Dolatian M, Khoramabadi M, Talebi A. Correlation of maternal-fetal attachment and health practices during pregnancy with neonatal outcomes. Electron Physician. 2016;8(7):2639-44. doi: 10.19082/2639. [PubMed: 27648191].
41. Shahhosseini Z, Gardeshi ZH, Pourasghar M, Salehi F. A review of affecting factors on sexual satisfaction in women. Mater Sociomed. 2014;26(6):378-81. doi: 10.5455/msm.2014.26.378-381. [PubMed: 25685081].

42. Jaafarpour M, Khani A, Khajavikhan J, Suhrabi Z. Female sexual dysfunction: prevalence and risk factors. J Clin Diagn Res. 2013;7(12):287780. doi: 10.7860/JCDR/2013/6813.3822. [PubMed: 24551663].

43. Brizendine L. The female brain. Broadway Books; 2006.

44. Booij SH, Bos EH, Bouwmans ME, van Faassen M, Kema IP, Oldehinkel AJ, et al. Cortisol and alpha-Amylase Secretion Patterns between and within Depressed and Non-Depressed Individuals. PLoS One. 2015;10(7):e0131002. doi:10.1371/journal.pone.0131002. [PubMed: 26148294].

45. Wang X, Cai L, Qian J, Peng J. Social support moderates stress effects on depression. Int J Ment Health Syst. 2014;8(1):41. doi: 10.1186/1752-4458-8 41. [PubMed: 25422673].

46. Syme ML, Klonoff EA, Macera CA, Brodine SK. Predicting sexual decline and dissatisfaction among older adults: the role of partnered and individual physical and mental health factors. J Gerontol B Psychol Sci Soc Sci. 2013;68(3):323-32. doi: 10.1093/geronb/gbs087. [PubMed: 23052362].

47. Vanwesenbeeck I, Have MT, de Graaf R. Associations between common mental disorders and sexual dissatisfaction in the general population. BrJ Psychiatry. 2014;205(2):151-7. doi: 10.1192/bjp.bp.113.135335. [PubMed: 24764543].

48. Ruiz-Munoz D, Wellings K, Castellanos-Torres E, Alvarez-Dardet C, Casals-Cases M, Perez G. Sexual health and socioeconomicrelated factors in Spain. Ann Epidemiol. 2013;23(10):620-8. doi 10.1016/j.annepidem.2013.07.005. [PubMed: 23932068].

49. Mazinani R, Akbari Mehr M, Kaskian A, Kashanian M. Evaluation of Prevalence of sexual dysfunctions and its related factors in women [In Persian]. Razi J Med Sci. 2013;19(105):59-66.

50. Tendais I, Figueiredo B, Mota J, Conde A. Physical activity, healthrelated quality of life and depression during pregnancy. Cad Saude Publica. 2011;27(2):219-28. [PubMed: 21359458].

51. Shishehgar S, Dolatian M, Majd HA, Bakhtiary M. Perceived pregnancy stress and quality of life amongst Iranian women. Glob J Health Sci. 2014;6(4):270-7. doi: 10.5539/gjhs.v6n4p270. [PubMed: 24999152].

52. Safarinejad MR. Female sexual dysfunction in a population-based study in Iran: prevalence and associated risk factors. Int I Impot Res. 2006;18(4):382-95. doi: 10.1038/sj.ijir.3901440. [PubMed:16395324].

53. Blurian Z, Ganjlu J. Sexual dysfunction and some related factors in women referred to health centers of Sabzevar. J Reprod Fert. 2007;8(2):163-70.

54. Verit FF, Verit A, Billurcu N. Low sexual function and its associated risk factors in pre- and postmenopausal women without clinically significant depression. Maturitas. 2009;64(1):38-42. doi: 10.1016/j.maturitas.2009.07.002. [PubMed: 19632073].

55. Pujols Y, Meston CM, Seal BN. The association between sexual satisfaction and body image in women. J Sex Med. 2010;7(2pt2):905-16.

56. Yoo H, Bartle-Haring S, Day RD, Gangamma R. Couple communication, emotional and sexual intimacy, and relationship satisfaction. I Sex Marital Ther. 2014;40(4):275-93. doi: 10.1080/0092623X.2012.751072. [PubMed: 24111536]. 